Volume 4 Nomor 1, Februari 2019, halaman 1-8

\title{
PENGARUH METODE PEMBELAJARAN TALKING STICK TERHADAP KEMAMPUAN KOMUNIKASI MATEMATIK SISWA
}

\section{THE INFLUENCE OF TALKING STICK LEARNING METHOD THROUGH STUDENTS MATHEMATICAL COMMUNICATION ABILITY}

\author{
Dartana $^{\mathbf{1}}$, Sri Hartini ${ }^{2}$, Rosyadi ${ }^{3}$ \\ ${ }^{1}$ SMP N 1 Kandanghaur, Jln. Raya Kandanghaur 45254, dartana02@ gmail.com \\ ${ }^{2,3}$ Universitas Wiralodra, Jln. Ir. H. Djuanda Km3 Singaraja Indramayu 45213, \\ hartini5511@yahoo.co.id, rosrosyadi@yahoo.co.id
}

\begin{abstract}
ABSTRAK
Tujuan penelitian ini adalah untuk mengetahui ada tidaknya pengaruh positif metode pembelajaran talking stick terhadap kemampuan komunikasi matematik siswa. Penelitian ini adalah penelitian eksperimen dengan variabel terikat kemampuan komunikasi matematik dan variabel bebasnya adalah metode pembelajaran. Dalam penelitian ini, untuk menganalisis data digunakan uji-t. Hasil analisis data diperoleh bahwa terdapat pengaruh positif metode pembelajaran tipe talking stick terhadap kemampuan komunikasi matematik siswa.
\end{abstract}

Kata kunci: Kemampuan Komunikasi Matematik, Segiempat, Metode Pembelajaran Takling Stick

\section{ABSTRACT}

The purpose of this research is to know whether or not there is a positive effect of talking stick teaching method on students' mathematical communication skills. This research is experimental research which has mathematical communication ability as dependent variable and learning method as independent variable. In this research, to the data analyze used test-t. From the data analyze obtained that, there is a positive effect of talking stick type learning method to students' mathematical communication ability.

Keywords: Mathematics Communication Ability, Rectangular, Talking Stick Learning Method

How to Cite: Dartana, Hartini, S., \& Rosyadi. (2019). Pengaruh Metode Pembelajaran Talking Stick terhadap Kemampuan Komunikasi Matematik Siswa. Mathline: Jurnal Matematika dan Pendidikan Matematika, Vol.4, No.1, 1-8.

\section{PENDAHULUAN}

Matematika memiliki peranan penting dalam perkembangan ilmu pengetahuan dan teknologi sehingga berdampak pada kemajuan suatu bangsa. Depdiknas (Purnamasari, 2014) menyatakan bahwa "Untuk menguasai dan mencipta teknologi di masa depan 
diperlukan penguasaan matematika yang kuat sejak dini”. Banyak persoalan yang disampaikan dengan bahasa matematika, misalnya dengan menyajikan persoalan atau masalah kedalam model matematika yang dapat berupa diagram, persamaan matematika, grafik dan tabel. Namun pada kenyataannya masih banyak siswa di sekolah yang tidak mengerti dengan bahasa matematika yang digunakan dalam pembelajaran untuk memecahkan masalah dalam matematika. Karim \& Saputera (2014) mengatakan "komunikasi merupakan proses penyampaian dari seseorang kepada orang lain secara langsung maupun secara lisan maupun tulisan dengan tujuan mengubah sikap dan tingkah laku". Menurut Hendriana \& Sumarmo (2014), "Kemampuan komunikasi matematik adalah bahasa simbol yang efisien, padat makna, memiliki sifat keteraturan yang indah dan kemampuan analisis kuantitatif, bersifat universal dan dapat di pahami oleh setiap orang kapan dan dimana saja”. Komunikasi yang dimaksud di sini adalah sebuah simbol yang berkaitan dalam soal-soal matematika yang dapat dimengerti oleh semua siswa, di mana cara penyelesaiannya tidak langsung diperoleh, akan tetapi melalui berbagai tahap terlebih dahulu. Selanjutnya Lestari \& Yudhanegara (2015) mengatakan bahwa kemampuan komunikasi merupakan kemampuan menyampaikan gagasan/ide matematis, baik secara lisan maupun tulisan serta kemampuan memahami dan menerima gagasan/ide gagasan orang lain secara cermat, analitis, kritis, dan evaluasi untuk mempertajam pemahaman". Berdasarkan uraian yang dikemukakan sebelumnya, dapat disimpulkan bahwa kemampuan komunikasi matematik adalah kemampuan siswa untuk membaca simbol-simbol matematika yang ada, sehingga dapat dimengerti dengen jelas. Dalam penelitian ini materi yang digunakan dalam kemampuan komunikasi matematik siswa adalah materi keliling dan luas bangun segiempat.

Namun, kenyataan dilapangan bahwa komunikasi matematik siswa, khususnya SMP masih rendah. Berdasarkan penelitian Susanto (2013) menunjukan bahwa kemampuan komunikasi dan keaktifan masih rendah dengan ditunjukan pencapaian yang kurang dari 50\%. Selaras dengan laporan TIMSS tahun 2011 yang menunjukan bahwa dalam penguasaan matematika Indonesia berada pada peringkat 38 dari 42 negara (Lestari, dkk., 2019). Sedangkan NCTM (2000) menyatakan bahwa kemampuan komunikasi matematik adalah essential part dalam matematika dan pendidikan matematika. Karena itu, dibutuhkan metode pembelajaran yang dapat melatih kemampuan komunikasi matematik siswa secara optimal. Dalam kegiatan pembelajaran, guru biasanya menjelaskan konsep secara informatif, memberikan contoh soal, dan memberikan soal-soal latihan. Hal ini juga diperkuat oleh Wahyuddin (Fauziah, 2010) yang menemukan bahwa guru matematika pada 
umumnya mengajar dengan metode ceramah dan ekspositori. Pada kondisi seperti itu, kesempatan siswa untuk menemukan dan membangun pengetahuannya sendiri tidak ada. Sebagian besar siswa tampak mengerti dengan baik setiap penjelasan atau informasi dari guru, siswa jarang mengajukan pertanyaan pada guru sehingga guru aktif sendiri menjelaskan apa yang telah disiapkannya. Siswa hanya menerima saja apa yang telah disiapkan oleh guru.

Menurut Arifin (2012) pembelajaran dalam arti sempit dapat diartikan "Sebagai suatu proses atau cara yang dilakukan agar seseorang dapat melakukan kegiatan belajar". Pada proses pembelajaran guru harus menggunakan metode pembelajaran yang tepat agar pembelajaran dapat berjalan efektif dan efisien sehingga tujuan pembelajaran tercapai. Komalasari (2010) menyatakan bahwa metode pembelajaran pada dasarnya merupakan bentuk pembelajaran yang tergambar dari awal sampai akhir yang disajikan secara khas oleh guru. Berdasarkan penjelasan para ahli di atas dapat disimpulkan bahwa metode pembelajaran adalah acuan yang digunakan dalam proses pembelajaran berupa pola-pola yang disusun secara sistematis untuk mencapai tujuan pembelajaran. Untuk mencapai tujuan tersebut, dibutuhkan metode pembelajaran yang efektif dan efisien. Oleh karena itu guru harus paham dan bijak dalam memilih jenis-jenis metode pembelajaran yang akan dilaksanakan di kelas.

Menurut Suprijono (2013), metode pembelajaran talking stick adalah suatu metode pembelajaran kelompok dengan bantuan tongkat, kelompok yang memegang tongkat terlebih dahulu wajib menjawab pertanyaan dari guru setelah siswa mempelajari materi pokoknya, selanjutnya kegiatan tersebut diulang terus-menerus sampai semua kelompok mendapat giliran untuk menjawab pertanyaan dari guru. Kurniasih (2015) mengemukakan metode pembelajaran talking stick merupakan satu dari sekian banyak metode pembelajaran kooperatif. Metode pembelajaran ini dilakukan dengan bantuan tongkat. Tongkat dijadikan sebagai jatah atau giliran untuk berpendapat atau menjawab pertanyaan dari guru setelah siswa mempelajari materi pelajaran. Pembelajaran dengan metode ini mendorong peserta didik untuk mengemukakan pendapat. Suprijono (2013) Pembelajaran dengan metode ini diawali dengan:

1) Penjelasan guru mengenai materi pokok yang akan dipelajari;

2) Peserta didik diberi kesempatan membaca dan mempelajari materi tersebut;

3) Guru mengambil tongkat yang telah dipersiapkan;

4) Tongkat tersebut diberikab kepada salah satu peserta didik; 
5) Peserta didik yang menerima tongkat tersebut diwajibkan menjawab pertanyaan dari guru demikian seterusnya;

6) Ketika stick bergulir bisa diiringi dengan nyanyian.

Dari penjelasan di atas dapat disimpulkan bahwa metode talking stick metode pembelajaran yang menggunakan perbantuan tongkat yang dipakai sebagai tanda seseorang mempunyai hak suara (berbicara) yang diberikan secara bergiliran/bergantian.

Berdasarkan uraian diatas, Tujuan penelitian ini adalah untuk mengetahui ada tidaknya pengaruh positif metode pembelajaran talking stick terhadap kemampuan komunikasi matematik siswa.

\section{METODE PENELITIAN}

Menurut Kadir (2010), populasi adalah suatu himpunan dengan sifat-sifat yang ditentukan oleh peneliti sedemikian serupa sehingga setiap individu atau variabel atau data dapat dinyatakan dengan tepat apakah individu tersebut menjadi anggota atau tidak. Jadi, yang dimaksud populasi adalah keseluruhan objek penelitian yang ditetapkan oleh peneliti dan ditarik kesimpulannya.

Populasi dalam penelitian ini adalah seluruh siswa kelas VII SMP Negeri 2 Losarang Tahun Pelajaran 2016/2017, dengan jumlah siswa 99 yang terbagi dalam 4 kelas, yaitu kelas VII A sampai dengan kelas VII D.

Tabel 1. Jumlah Siswa Kelas VII SMP Negeri 2 Losarang

\begin{tabular}{crc}
\hline No & Kelas & Jumlah \\
\hline 1. & Kelas VII A & 24 \\
2. & Kelas VII B & 25 \\
3. & Kelas VII C & 25 \\
4. & Kelas VII D & 25 \\
\hline & Jumlah & 99 \\
\hline
\end{tabular}

Menurut Kadir (2010), sampel adalah himpunan bagian atau sebagian dari populasi yang karakteristiknya benar-benar diselidiki. Sedangkan menurut Sugiyono (2011), sampel adalah bagian dari jumlah dan karakteristik yang dimiliki oleh populasi. Jadi, sampel adalah bagian dari populasi yang akan diteliti.

Menurut Senjaya (2017), cluster random sampling adalah pengambilan sampel berupa kelompok anggota tertentu dari populasi yang anggota-anggotanya merupakan kelompok-kelompok atau dapat dikelompokan menjadi beberapa kelompok. Populasi dari cluster merupakan subpopulasi dari total populasi. Unsur-unsur dalam cluster sifatnya 
tidak homogen, yang berbeda dengan unit-unit elementer dalam strata. Tiap cluster mempunyai anggota yang heterogen menyerupai populasi sendiri.

Dalam penelitian ini pengambilan sampel menggunakan teknik Cluster Random Sampling, sehingga tiap kelas yang akan dijadikan sampel mempunyai peluang yang sama untuk dipilih dengan cara diundi. Sebelum melakukan pengundian pada tiap pasangan kelas, peluang setiap kelas dihitung terlebih dahulu dengan menggunakan rumus kombinasi agar mendapatkan peluang yang sama.

$$
\begin{aligned}
& { }_{\mathrm{N}} \mathrm{Cn}=\frac{N !}{n !(N-n) !} \quad(\text { Nazir, 2011) } \\
& 4 \mathrm{C} 2=\frac{4 !}{2 !(4-2) !}=\frac{4 !}{2 !(2) !}=\frac{4 \times 3 \times 2 \times 1}{2 \times 1 \times 2 \times 1}=6
\end{aligned}
$$

Sehingga setiap kelas mempunyai peluang $\frac{1}{6}$, sehingga di dapat kombinasi AB, AC, AD, BC, BD, dan CD. Setelah di dapat kombinasi kemudian diundi dan hasil yang didapat dijadikan sebagai sampel peneltian.

Setelah dilakukan pengundian diperoleh kelas VII B yang kemudian ditetapkan sebagai kelas eksperimen yang diberi perlakuan metode pembelajaran talking stick (tongkat berbicara) dan kelas VII D yang kemudian ditetapkan sebagai kelas kontrol yang diberi perlakuan metode pembelajaran ekspositori.

Desain penelitian adalah perencanaan penelitian yang disusun untuk melaksanakan penelitian. Menurut Nazir (2011), desain dari penelitian adalah semua proses yang diperlukan dalam perencanaan dan pelaksanaan penelitian, dan desain penelitian ini harus mengikuti metode penelitian. Sedang menurut Lestari \& Yudhanegara (2015) bahwa, desain penelitian adalah keseluruhan dari perencanaan untuk menjawab pertanyaan penelitian dan mengantisipasi beberapa kesulitan yang mungkin timbul selama proses penelitian. Selain itu, menurut Nazir (2011), penelitian eksperimental adalah penelitian yang dilakukan dengan mengadakan manipulasi terhadap objek penelitian serta adanya kontrol. Tujuan penggunaan metode eksperimen dalam penelitian ini adalah untuk mengetahui pengaruh suatu metode pembelajaran dengan membandingkan hasil kelompok eksperimen yang menggunakan metode talking stick dan hasil kelompok kontrol yang menggunakan metode pembelajaran ekspositori. Adapun desain penelitiannya yaitu:

\section{$\mathrm{R} \quad \mathrm{X}_{1} \mathrm{O}$ \\ $\mathrm{R} \quad \mathrm{X}_{2} \quad \mathrm{O}$}

Keterangan:

R : Random untuk menentukan sampel. 
$\mathrm{X}_{1} \quad$ : Perlakuan untuk kelas eksperimen

$\mathrm{X}_{2} \quad$ : Perlakuan untuk kelas kontrol

O : Tes akhir (Posttest)

\section{HASIL DAN PEMBAHASAN}

Adapun data hasil tes akhir kelas eksperimen dan kelas kontrol setelah dilakukan pengolahan data dapat dilihat dari tabel berikut.

Tabel 2. Rata-rata, Varians dan Simpangan Baku

\begin{tabular}{lcc}
\hline \multicolumn{1}{c}{ Nilai } & Kelas Eksperimen & Kelas Kontrol \\
\hline Jumlah Siswa & 25 & 25 \\
Rata-rata & 34,900 & 31,640 \\
Varians & 33,000 & 19,740 \\
Simpangan Baku & 5,745 & 4,443 \\
\hline
\end{tabular}

Dari tabel 2 di atas menunjukan bahwa rata-rata kemampuan komunikasi matematik siswa pada kelas eksperimen dari 25 siswa adalah 34,900, variansnya 33,000 dan simpangan bakunya 5,745. Sedangkan rata-rata kemampuan komunikasi matematik siswa pada kelas kontrol dari 25 siswa adalah 31,640, variansinya 19,740 dan simpangan bakunya 4,443. Berdasarkan skor rata-rata yang diperoleh dapat dikatakan skor rata-rata kemampuan komunikasi matematik siswa pada kelas eksperimen lebih tinggi dari skor rata-rata kelas kontrol dan dari data tersebut diperoleh juga perbedaan antara kelas eksperimen dan kelas kontrol, yaitu data kelas eksperimen lebih menyebar dan bervariasi dibandingkan dengan data kelas kontrol. Tetapi perbedaan tersebut belum menjawab ada atau tidaknya pengaruh positif pembelajaran tipe talking stick terhadap komunikasi matematik siswa. Jadi, selanjutnya diperlukan uji hipotesis terlebih dahulu yaitu uji normalitas dan homogenitas. Setelah normalitas dan homogenitas dua varians dipenuhi, maka selanjutnya menguji kesamaan dua rata-rata yaitu dengan menggunakan uji-t.

Tabel 3. Data Uji - $t$

\begin{tabular}{lccccc}
\hline \multicolumn{1}{c}{ Kelas } & Rata-rata & Varians & $\boldsymbol{S}_{\text {gab }}$ & $\boldsymbol{t}_{\text {hitung }}$ & $\boldsymbol{t}_{\text {tabel }}$ \\
\hline Eksperimen & 34,900 & 33,000 & \multirow{2}{*}{26,37} & 2,244 & 2,011 \\
\hline Kontrol & 31,640 & 19,740 & & & \\
\hline
\end{tabular}

Berdasarkan tabel di atas, dengan taraf signifikan $\alpha=0,05$ dan derajat kebebasan $(\mathrm{dk})=48$ diperoleh $t_{\mathrm{obs}}=2,244$ dan $t_{\mathrm{knitis}}=2,011$ dari data tersebut, dapat disimpulkan bahwa $t_{\mathrm{obs}}>t_{\mathrm{knti} i \mathrm{~s}}$. Karena $t_{\mathrm{obs}}>t_{\text {krntis, }}$, maka $\mathrm{H}_{0}$ ditolak, artinya kedua kelas tersebut mempunyai perbedaan dengan 
skor rata-rata dan varian kelas eksperimen lebih besar dari pada kelas kontrol, sehingga ada pengaruh positif metode pembelajaran tipe talking stick terhadap komunikasi matematik siswa.

\section{KESIMPULAN}

Dari penelitian yang penulis lakukan di SMP Negeri 2 Losarang, maka dapat ditarik kesimpulan bahwa kemampuan komunikasi matematik siswa yang menggunakan metode pembelajaran talking stick dan kemampuan komunikasi matematik siswa yang menggunakan metode ekspositori mempunyai perbedaan, dan skor rata-rata kelas eksperimen lebih besar dari skor rata-rata kelas kontrol, dengan kata lain terdapat pengaruh positif metode talking stick terhadap kemampuan komunikasi matematik siswa.

\section{DAFTAR PUSTAKA}

Arifin, Z. (2012). Metode Penelitian. Bandung: Remaja Rosda Karya.

Fauziah, A. (2010). Peningkatan Kemampuan Pemahaman dan Pemecahan Masalah Matematik Siswa SMP Melalui Strategi REACT. Jurnal Pendidikan, Vol.30, No.1, $1-13$.

Hendriana, H \& Sumarno, U. (2014). Penilaian Pembelajaran Matematika. Bandung: PT Refika Aditama.

Kadir. (2010). Statistika Untuk Penelitan Ilmu-Ilmu Sosial Dilengkapi Dengan Output Program SPSS. Jakarta: Rosemata Sampurna.

Karim \& Saputera. S. N. H. (2014). Pengaruh Model Pembelajaran Kooperatif tipe Rotating Trio Exchange (RTE) Terahadap Kemampuan Komunikasi Matematis Pada Siswa SMP. Jurnal Pendidikan Matematika, Vol. 2, No. 3, 271-278.

Komalasari, K. (2010). Pembelajaran Kontekstual Konsep dan Aplikasi. Refika Aditama. Bandung.

Kurniasih, I. (2015). Ragam Pengembangan Model Pembelajaran Untuk Peningkatan Profesionalitas Guru. Kata Pena. Jakarta.

Lestari, K. E., \& Yudhanegara, M. R. (2015). Penelitian Pendidikan Matematika (Panduan Praktis Menyusun Skripsi, Tesis, Kualitatif, dan Kombinasi Disertai Dengan Model Pembelajaran Dan Kemampuan Matematis). Bandung: PT Refika Aditama.

Lestari, W. D., Kusumah, Y. S., \& Dewanto, S. (2019). Peningkatan Kemampuan Pemecahan Masalah Matematis Siswa SMP Melalui Pembelajaran Group Investigation Berbantuan Proyek. Indomath: Indonesian Mathematics Education, Vol.2, Issue 1, 1-8.

Purnamasari, Y. (2014). Pengaruh Model Pembelajaran Kooperatif Tipe Teams Games Tournament (TGT) Terhadap Kemandirian Belajar dan Peningkatan Kemampuan Penalaran dan Koneksi Matematik Peserta Didik SMPN 1 Kota Tasikmalaya. Jurnal Pendidikan dan Keguruan, Vol.1, No.1, 1-11.

Nazir, M. (2011). Metode penelitian. Bogor: Penerbit Ghalia Indonesia.

NCTM. (2000). Principles and Standards for School Mathematics. Reston. VA: NCTM.

Senjaya, A. J. (2017). Statistika Terapan untuk Penelitian Bidang Pendidikan dan Pengajaran, Indramayu: FKIP Unwir Press.

Sugiyono. (2011). Metode Penelitian Pendidikan Pendekatan Kuantitatif, Kualitatif dan $R \& D$. Bandung: Alfabeta. 
8 Pengaruh Metode Pembelajaran Talking Stick terhadap Kemampuan Komunikasi Matematik Siswa

Suprijono, A. (2013). Cooperative Learning (Teori dan Aplikasi Paikem).Yogyakarta: Pustaka Pelajar.

Susanto, S. T. (2013). Peningkatan Komunikasi matematik Dan Keaktifan Siswa Melalui Pendekatan Realistic Mathematics Education (RME) Pokok Bahasan Segi Empat. Skripsi. Universitas Muhannadiyah Surakarta: Tidak diterbitkan. 